\title{
AS RELAÇÕES DE GÊNERO NO CORPO: OLHARES DE ESTUDANTES DE LICENCIATURA EM EDUCAÇÃO FÍSICA
}

\author{
Kelly Cristiny Martins Evangelista \\ TADEU JoÃo RibEIRO BAPTISTA \\ Universidade Federal de Goiás (UFG), Goiânia, Goiás, Brasil
}

\begin{abstract}
Resumo: Este trabalho tem como intenção analisar como vêm sendo tratadas as relações de gênero, a partir do corpo, por acadêmicos de licenciaturas de Educação Física do município de Goiânia, buscando identificar como as questões de gênero atravessam e constituem as relações. A abordagem elencada para realizar a análise dos dados pesquisados é qualitativa. Trata-se de um estudo descritivo de caráter transversal, o local elencado para os estudos foram dois cursos de Educação Física de instituições públicas da cidade de Goiânia, para coleta de dados a técnica utilizada foi o questionário, aplicados para 24 acadêmicos. $O$ estudo demonstra que mesmo que algumas pessoas demonstrem comportamentos de gênero e sexualidade distintos do tradicional, este processo de educação parece não ter atingido sua relação com as práticas da cultura corporal.
\end{abstract}

Palavras-chave: Gênero. Corpo. Educação. Educação física.

INTRODUÇÃO

As relações sociais podem ser pensadas a partir de diversos ângulos, uma das possibilidades é a análise a partir da concepção de gênero, que tenta explicitar acerca das mediações que levam à formação da noção cultural e 
social de feminino e masculino. O corpo é sítio inicial nessa conformação, mas não é o único marcador, esses comportamentos são aprendidos e reinaugurados a cada nascimento, bem como na maneira como cada ser humano vai sendo inserido no contexto do seu grupo de referência.

Existem diversos estudos que apontam interesse em descobrir as profundidades do corpo do ponto de vista de seus sentimentos e de suas relações com a natureza'. Oliveira (2000) refere-se ao corpo como um elemento central no processo de escolarização, como resultado de um projeto de modernidade que se relaciona com o interesse ocidental de civilização. Para isso, é necessário um grande investimento, ao relacionar corpo, gênero e educação é possível pensar as inter-relações existentes entre eles.

Refletir sobre essa temática e seus desdobramentos históricos e sociais parece relevante, considerando a modernidade e as características geopolíticas do Brasil, pois os debates de gênero convivem em conflito entre o permitido e o proibido, de maneira tal que a academia ainda é um local onde esse pensamento vem se construindo com alguma liberdade. Handman (2014) lembra que mulheres foram impedidas e segregadas desse espaço, até os anos de 1930, momento no qual era rara a circulação feminina nas universidades.

Algumas pesquisas revelaram que na região Centro-Oeste do Brasil a diferença salarial demonstra que as mulheres recebem em média $82,72 \%$ do salário dos homens, mesmo considerando que elas estudam mais do que eles (9,61 anos em média para elas e 7,91 anos para eles) de acordo com Aguiar e Vaz (2016).

Outras fontes demonstram mais informações, as quais complementam essa totalidade. O mapa da violência no Brasil, de 2015, trouxe dados alarmantes para debates de gênero e violência, pois o corpo feminino é local permanente de violências, isso é avaliado não apenas pelas mortes, mas pela forma como o corpo é manipulado em atos de violência como os espancamentos, estupros, assassinatos, entre outros. O Brasil ocupou em 2015 a 5a posição entre os países com maior índice de homicídios femininos. Discutir as perspectivas culturais, sociais e históricas é relevante para compreender a relação em construção entre humanos, desigualdades e avanços possíveis, inclusive na educação (BANDEIRA, 2017).

Assim, o problema deste texto é analisar como têm sido tratadas as questões de gênero no corpo pelos acadêmicos de licenciatura em educação física da cidade de Goiânia? Para responder a este problema, optou-se por apresentar uma revisão de literatura dos pontos centrais sobre o tema, a metodologia e, finalmente, a análise e discussão dos dados. 
UM PERCURSO TEÓRICO: UM BREVE DIÁLOGO COM A LITERATURA SOBRE CORPO E GÊNERO

Para refletir sobre as possibilidades do debate sobre o gênero a partir da intervenção sobre o corpo, principalmente entre estudantes de cursos de licenciatura em educação física, e as possibilidades de educação do corpo e os seus impactos sobre as questões de gênero, dividimos a construção deste referencial teórico em dois pontos, a saber: a construção de gênero e educação; e a perspectiva da história e da corporalidade.

\section{CONSTRUÇÃo DO GÊNERO}

Para falar sobre as relações entre homens e mulheres na sociedade nos apoiamos no conceito de gênero, que surgiu em um cenário específico. Desde a sua primeira interpretação até hoje muito se deve ao desenvolvimento dos movimentos sociais e estudos feministas.

Piscielli (2001) diz que o conceito de gênero teve visibilidade significativa a partir de 1980, para a autora ele transformou a forma de pensar o feminino e o masculino, abrindo caminhos para maior reflexão sobre a temática. Ao estudar gênero deve-se compreendê-lo como uma construção social. Segundo Altmann e Sousa (1999), gênero pode ser compreendido como a construção social que uma dada cultura estabelece ou elege em relação a homens e mulheres, com relação à vestimenta, a comportamentos, hábitos, gestualidades, acessórios, entre outros.

Chabaud-Rycheter (2014) diz que as pesquisas sobre gênero, identidade e mulheres foram historicamente marginalizadas, para expor essas investigações foi preciso romper com as "normasculas", que, como explica a autora, são as normas inclinadas ao masculino. Isso resultou em um apagamento de asserções, como a percepção das relações de poder marcadas pelo sexo.

O conceito de gênero emergiu dos estudos feministas, e é importante compreender quais os nexos que envolveram a formulação do termo. Piscitelli (2002) relata que sua exposição se deu em um momento de grande mobilização feminina, em que existiam diversas demandas, a produção de textos, imagens, diálogos e encontros, cujos focos se voltaram para a necessidade da defesa dos direitos iguais entre homens e mulheres. Nesse momento ocorreu uma forte articulação nos movimentos sociais de mulheres.

Por sua vez, no campo acadêmico existia interdição em relação à participação feminina. Handman (2014) fala sobre a segregação nesses espaços formativos de profissionais. Segundo essa pesquisadora, em 1930, 
por exemplo, eram raras as mulheres que faziam pesquisas científicas em campo. Piscitelli (2002) avalia no contexto histórico de reconhecimento do termo que existiam desenvolvimentos diferenciados para as vertentes feministas, contudo a autora aponta convergências, como, no final dos anos 1960, quando as feministas tinham o pensamento comum em relação ao lugar que a mulher ocupava na sociedade.

A subordinação feminina é pensada como algo que varia em função da época histórica e do lugar do mundo que se estude. No entanto ela é pensada como universal, na medida em que ocorre em todas as partes e em todos os períodos históricos conhecidos (PISCITELLI, 2002, p. 2).

As correntes feministas foram questionadoras incansáveis dessa subordinação, e Piscitelli (2002) apresenta que elas negavam a naturalidade do caráter de sujeição da mulher, justificando que as noções presentes na construção desse pensamento não são naturais, mas construídas historicamente. Diante da indignação que se espalhava, diversas estratégias foram desenvolvidas, e a entrada de mulheres na universidade, na política e na produção do conhecimento é citada como importante nessa contextualização. Grandes mobilizações também compunham as medidas de combate ao pensamento contraditório. As forças foram somadas contra a ideia falsa de subordinação feminina de ordem natural (PISCITELLI, 2002).

Walzer-Lang (2001) salienta que os homens também aderiram às reivindicações feministas em maior ou menor grau. De acordo com os seus estudos, em 1975 surgiram grupos de homens antissexistas, que entendiam os principais interesses dos movimentos sociais em dialogar com outros acerca das desigualdades nas relações entre homens e mulheres. $O$ pesquisador localiza no ano de 1996 em Québec a decisão coletiva desses grupos se denominarem pró-feministas, o que significava para eles não utilizar o termo feminista exclusivamente para as mulheres.

Temos que entender as relações de gênero como um constructo historicamente determinado a partir de uma série de conexões e, entre estas, relações de produção. Também as diferenças biológicas são consideradas, mas não são exclusivas, pois elas existem e se ligam com o controle, uma vez que o sujeito não pode ser visto fora das suas condições materiais de existência, a partir das propostas de Marx e Engels (1998). Entende-se que esse processo não é algo imediato e nem mesmo individual, a construção do masculino e do feminino ocorre na realidade e envolve uma série de mediadores sociais.

A divisão por gênero pode em primeiro momento parecer inofensiva, isto é, homens para um lado e mulheres para o outro, contudo a relação se 
desenvolve de forma que se configuram comportamentos, estereótipos, formas de dominação do corpo do outro, aparecendo nas relações de trabalho e findando na concepção que as formas binárias são modos de separar o homem e a mulher e diferenciar o tratamento a partir disso, como se fosse possível enquadrar os seres humanos em polos, dualidades e formas pré-determinadas.

O movimento feminista foi e ainda persiste como um dos tensionamentos mais radicais na denúncia de situações desiguais. As questões de gênero aparecem na articulação com a totalidade, entendendo não ser possível uma mudança significativa enquanto a desigualdade permear toda a organização humana. Nessa perspectiva, as próprias contradições estabelecidas a partir do modo de produção provocam separações entre os seres humanos e a busca de domínio de um ser humano sobre o outro (MARX, 2010).

Mulheres e homens sobrevivem em determinado momento histórico, são sujeitos da realidade social, que é produto de diversas mediações. Marx (1996) afirmou que a história é realizada pelos humanos, os quais "[...] não a fazem sob circunstâncias de sua escolha e sim sob aquelas com que se defrontam diretamente legadas e transmitidas pelo passado" (MARX, 1996, p. 5), assim os sujeitos vão se organizando, permeando entre o objetivo e o subjetivo. Desse modo, as relações de gênero se constroem a partir de processos educativos, estabelecidos por suas particularidades históricas, e por suas relações com outros seres humanos. Este é um processo educativo em uma perspectiva ampla, considerando que a educação não ocorre apenas no espaço escolar.

\section{HISTÓRIA E CORPORALIDADE}

A preocupação com a formação e educação do corpo no Brasil teve uma forte relação com a prática de exercícios. De acordo com Castellani Filho (1994), a Educação Física e o militares foram atores nessa conformação. Legislações com indicação de atividades fizeram parte desse contexto. $\mathrm{O}$ próprio Ling, criador da ginástica sueca, propunha uma ginástica estética e, na parte escolar, diferenciações para homens e mulheres, considerando as características biológicas de cada sexo (SOARES, 2001).

Ao olhar a legislação no Brasil, Marinho (1984) conta que, em 1852, foi apresentado um regulamento para instrução pública primária imperial no Rio de Janeiro, que era naquele período a sede do país, um projeto para a civilização moral, intelectual e corporal. $O$ documento trouxe a Educação Física em pauta, indicada como um componente curricular para a escola, cujos conteúdos deveriam ser direcionados para cada sexo. 
Assim o autor pontua que Fernando Azevedo definiu a prática da ginástica para ambos os sexos, para as mulheres uma Educação Física higiênica, com atividades manuais, jogos e esportes considerados menos agressivos. Nesse caso, o propósito era, naquele momento, apresentar o ideal de construir uma mulher compulsoriamente mãe, pessoa de comportamentos delicados, restritos e serenos (MARINHO, 1984).

Uma das preocupações emergentes com a educação do corpo escolar dizia respeito às características biológicas da faixa-etária e dos gêneros, o que permitiria criar programas específicos aos diferentes padrões de desenvolvimento (BOMBASSARO; VAZ, 2009, p. 121).

A Educação Física indicava exercícios bem diferentes para homens e mulheres, aparentemente justificando individualidades de cada sexo, contudo isso não passa de uma naturalização de comportamentos e, desse modo, ela se apropria dos pressupostos generificados para suas atividades, limitando as possibilidades de ambos.

Rui Barbosa, Fernando Azevedo e todos aqueles que se viram influenciados por aquele ideário, além de oportunizarem aos homens, maiores oportunidades de desenvolverem em destrezas físicas, acabaram por reforçar o pensamento dominante acerca do papel da mulher na sociedade brasileira, qual seja, aquele que, ao ventilar a urgência de prepará-la fisicamente para a maternidade, estigmatizou sua imagem, associando-a, quase que somente à ideia de mãe (CASTELLANI FILHO, 1994, p. 60).

Essa compreensão cultural de papéis femininos e masculinos foi transposta e reforçada na Educação Física. Castellani Filho (1994) conta que em 1941 as mulheres foram interditadas de praticar de forma oficial algumas modalidades esportivas. Em 1965, outro entrave foi publicado, a deliberação do Conselho Nacional de Desporto (CND) segundo a qual as mulheres foram proibidas de praticarem quaisquer formas de lutas, além de rugby, futebol, basebol, polo aquático e halterofilismo. Apenas em 1986 o CND revogou as proibições de 1965.

Destarte, é possível identificar características relacionadas ao sexo e ao gênero no contexto dos processos de educação dos corpos. Isso significa tratar muito mais do que os elementos meramente biológicos, considerando a constituição de mediações e determinações para os sujeitos na sociedade, sobremodo, na organização social da produção capitalista. 


\section{Metodologia}

Este trabalho tem como foco pensar como a relação entre corpo e gênero ganha relevância em toda a investigação, inclusive nas licenciaturas, porque são locais de formação inicial para professores, lugar de formação do conjunto de práticas que influenciarão no desenvolvimento profissional e político dos acadêmicos.

O método escolhido para tratar o objeto é o materialismo dialético. Trata-se de um estudo descritivo de caráter transversal. O local elencado para os estudos são dois cursos de licenciatura em Educação Física, em Goiânia, sendo que o estudo foi autorizado pelo comitê de ética em Pesquisa da Universidade Federal de Goiás, com o número de parecer 2.086.244 de 2017.

A técnica adotada na coleta de dados foi o questionário elaborado especialmente para esta pesquisa, o qual procurou atender ao problema do estudo e foi aplicado a 24 acadêmicos matriculados do primeiro ao oitavo período em dois cursos de licenciatura de universidades públicas da cidade de Goiânia. Os critérios de inclusão eram que os alunos possuíssem mais de 18 anos, estivessem presentes na sala de aula na hora da aplicação do teste, e assinassem o Termo de Consentimento Livre e Esclarecido (TCLE) se concordassem em participar deste estudo. O questionário foi aplicado nos meses de junho e julho de 2017.

A abordagem adotada para realizar a análise dos dados pesquisados foi de característica quanti-qualitativa, por se entender que existe a necessidade de interpretar a realidade do objeto, tanto por meio de dados numéricos como subjetivos, considerando que estas informações podem ser analisadas em conjunto (SÁNCHEZ-GAMBOA; SANTOS FILHO, 2013).

\section{OlHANDO PARA O DISCURSO E A REALIDADE: EXPECTATIVAS, VIGILÂNCIA E CON- TROLE DO CORPO NAS RELAÇÕES DE GÊNERO}

Segundo Louro (2000), as pedagogias contemporâneas são processos pelos quais os sujeitos são marcados por conceitos, disseminam padrões, permitindo que as diferenças sejam expostas, negadas. Assim, os discursos e a cultura são instrumentos que viabilizam essas aprendizagens. Ser homem e mulher acontece por meio dessas vivências cotidianas, inicia-se antes mesmo do nascimento e é algo que está relacionado às expectativas de cada cultura. O processo das aprendizagens vai se desenvolver nos vínculos familiares, escolares, religiosos e permeia todas as relações de forma contínua.

Manifestar sobre essa demanda exige noções de equidade, já que é notória e explícita a relação de poder existente. Homens, mulheres, meninas 
e meninos não convivem com igualdade, é preciso amplo debate sobre essa disparidade, considerando que diferentes elementos presentes nas diversas manifestações presentes entre os seres humanos atribuem valores diferentes às classes sociais, aos sexos e a seus comportamentos específicos de acordo com o que é previsto por normas e regras definidas pelos grupos hegemônicos.

Nesse sentido, a pesquisa tenta trazer um pouco das disparidades atuais. Para isso foi aplicado um questionário a 24 alunos do curso de Educação Física de duas instituições públicas, os quais se disponibilizaram para responder ao instrumento. Estas pessoas tinham idade entre 19 a 38

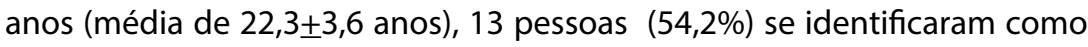
pertencentes ao sexo feminino, 11 ao sexo masculino $(45,8 \%)$ e do total de 24, apenas dois marcaram o gênero diferente do seu sexo, porquanto consideraram o seu sexo de nascimento diferente do seu comportamento sexual, ou seja, usam roupas, acessórios e demonstram sentimentos, os quais, são considerados socialmente como do sexo oposto. Estas pessoas que marcaram o gênero diferente do sexo biológico (de nascimento) o fizeram considerando os comportamentos. O percentual de pessoas que se identificam com o sexo feminino, de $54,2 \%$, se aproxima do quantitativo de mulheres que cursavam o ensino superior nos anos 2000, de acordo com o estudo de Guedes (2008), de 52,8\%.

Do ponto de vista da sexualidade, as 13 mulheres assumiram a condição de heterossexualidade, e entre os 11 homens, 1 se apresentou como homossexual, 3 como bissexuais e 7 como heterossexuais. $O$ dado relacionado às mulheres se assemelha a outro estudo feito com 34 professores de Educação Física em escolas públicas de Goiânia. Nessa pesquisa, todas as pessoas entrevistadas se identificaram como sendo heterossexuais (PÁDUA et al., 2012).

Quanto ao estado civil, apenas uma pessoa é casada e as outras 23 são solteiras. A renda mensal foi informada por sete participantes, para eles a renda variou de $R \$ 450,00$ a $R \$ 1300,00$, os outros 17 não possuem ou não informaram a sua renda. Estes dados demonstram a precariedade das condições financeiras individuais, embora não tenha sido foco deste estudo analisar a renda familiar, a qual pode ser diferenciada das informações aqui apresentadas.

Uma das questões trazia a pergunta sobre a possibilidade de definir sexo/gênero de uma pessoa por seu comportamento, ou seja, se existe uma forma predeterminada de se apresentar ou agir para as pessoas. A maior parte afirmou que não, muitos apontaram uma perspectiva de análise considerável, a cultura, normas e individualidades foram citadas como importantes nesse processo. Além disso, as relações de poder decidir também foram consideradas. Entre os que disseram que a forma de agir não define o sexo 
ou gênero das pessoas, identificamos frases como: "Não. Um homem pode ter o comportamento comum ao gênero feminino sem deixar de ser homem" (N6), ou"não, muitas vezes as pessoas gostam de coisas que a sociedade julga do sexo oposto" (N19).

Por outro lado, os que disseram sim - ou seja, que os comportamentos definem a questão do sexo ou do gênero - fizeram afirmações como: "sim, homens desde a infância são condicionados aos esportes com bola, principalmente o futebol. No futebol os homens possuem maiores habilidades" (N23), ou também "sim, visto que comportamentos expressam ideais, mas não 'encaixotando' determinados comportamentos como de homem e outros como de mulher"(N8). Ser homem e mulher acontece no cotidiano, como aponta Soares (2006) isso se inicia antes mesmo do nascimento, a partir das expectativas de cada cultura, permanecendo de modo ininterrupto ao longo da vida das pessoas.

Ainda em relação à questão da lógica de existência de um comportamento preexistente, os acadêmicos que defenderam uma lógica que condiciona/limita/define comportamentos justificaram, como pôde ser visto em algumas falas, existirem padrões tradicionais, contudo, uma parte significativa das mulheres e homens expôs discordar desse fato, porquanto defendem que apesar das expectativas, esse tipo de questão deveria ter sido superada.

O corpo, assim como as questões de sexo e gênero, não pode ser pensado fora de suas condições de existência. Para Baptista (2013) o corpo, assim como o trabalho,

[...] é natural, portanto histórico, haja vista as distintas relações entre os seres humanos. De um lado existe a importância das relações biológicas, como a procriação a própria existência física, constituídas a partir da relação mínima entre dois seres, que estabelecem as suas relações, de forma a garantir a sua existência, e as condições de produção de vida, que determinam como estes seres, ou mesmo grupos, se constituem entre si. De outro lado, o corpo é constituído e deve atender as exigências presentes no seu período histórico, visto como, em cada momento, as relações de produção e de associação grupal exigem a construção de novos modelos, assim como de capacidades e habilidades diferenciadas (BAPTISTA, 2013, p. 69).

Partindo dessas assimilações o autor aponta que o modelo de corpo que atende ao sistema produtivo é implementado por um vasto processo educativo, envolvendo diversas instâncias, submetidas ao sistema econômico. Essa realidade é avaliada como um entrave ao desenvolvimento dos seres humanos e de suas corporalidades. 
Apesar das diferenciações perceptíveis, existe um ponto de interesse que não se relaciona com a categoria sexo/gênero, trata-se da valorização dos exercícios de resistência ou de atividades ligadas às academias de ginástica, visto que mais da metade das pessoas afirmaram frequentarem academias de ginástica. Exercícios resistidos também estão entre as modalidades que mais agradaram aos discentes no curso. No estudo realizado por Cardoso et al. (2009), apenas uma pequena parcela dos jovens entrevistados, independente de sua orientação sexual, praticam atividades como a musculação.

"Os corpos são educados por toda realidade que os circunda, por todas as coisas com as quais convivem, pelas relações que se estabelecem em espaços definidos e delimitados por atos de conhecimento" (SOARES, 2006, p. 109). A autora traz a noção das pretensões induzidas por regras morais construídas a partir da cultura, assim as condutas estão ligadas às formas de dominação do corpo do outro, assim como ao próprio corpo. Desse modo, a realização das diferentes práticas corporais faz parte de uma dimensão mais ampla da educação.

A cultura e as instituições, como a família e a escola, são importantes nesse processo, de limitar os corpos, as expressões, as linguagens, os movimentos e atividades desenvolvidas. Esse controle corporal é consolidado ao passo que se criam normas que regulam os comportamentos, num processo diário de educação do corpo, os quais procuram delimitar aspectos vinculados ao sexo e ao gênero a partir da corporalidade. As diferentes relações sociais agem na contensão dos sentimentos, controle da agressividade e repressão da sensibilidade, ou seja, interferem nas formas de ser das pessoas.

Os dados coletados apontam, também, para a perspectiva de que os alunos percebem no corpo as diferenças culturais sexistas. Quando foram questionados sobre as diferenças visíveis entre as mulheres e os homens no curso, uma grande parte colocou que elas são notáveis, como denota a resposta seguinte de um aluno:"nas partes práticas pessoas que tiveram melhor formação de práticas corporais quando crianças apresentam mais facilidades na compreensão e também na execução"(N7), uma aluna afirmou "a quantidade de homens com mais facilidade nas práticas são maiores que as mulheres"(N2). Ao analisar algumas respostas no questionário, ficaram evidentes as dissonâncias tanto entre os homens quanto entre as mulheres, os quais reconhecem que os sujeitos incorporam as marcas de gênero no corpo, uma vez que essa perspectiva dominante ainda é irrefutável e difícil de ser transformada.

A percepção de que existem diferenças é quase total entre os participantes da pesquisa, a força corporal - potência, participação efetiva, habilidade - é muito enfatizada no masculino, já no que se refere à mulher 
citam-se a pouca habilidade, flexibilidade, interdição em atividades, restrição na infância aos conteúdos e preconceito. Nesse sentido, uma aluna escreveu: "Se a mulher é proibida de jogar futebol, obviamente seu repertório motor estará limitado dentro desta prática" (N4). Pensando de forma imediata, parece que esses são pequenos problemas que podem ser revolvidos com facilidade, entretanto os discursos presentes revelam a realidade dada na desigualdade. As violências no corpo se dão de formas distintas; reprimir, restringir, estar no mesmo ambiente e não ter acesso às mesmas possibilidades por reservas de formação cultural são algumas manifestações que merecem maior atenção.

Podemos nascer do sexo feminino ou masculino, mas as feministas rejeitam a ideia tradicional segundo a qual nosso sexo determina necessariamente (biologicamente ou pela vontade de Deus) nossos traços psicológicos, implicando assim, que vamos e devemos concretizar algumas formas de trabalho e determinados papéis sociais (HOLMSTRON, 2014, p. 344).

Esse é um dos grandes pontos a serem revisitados cotidianamente: a determinação por sexo/gênero, de qualquer lado que se encontrar, será limitante. Kian (2014), ao expor o pensamento de E. Goffman acerca da organização social e diferenciação entre sexos, aponta que o sociólogo considera que a marcação do sexo biológico se expressa de formas diversas, cotidianas e banais; a separação dos banheiros, para ele, é uma forma sutil de relembrar as diferenças biológicas. Também é perceptível uma divisão sexual do trabalho, socialização diferenciada para homens e mulheres que participam dos arranjos sociais estereotipados. E estes são elementos importantes do ponto de vista de uma educação do corpo, estabelecido pelo sexo, mais do que pelo gênero ou pela sexualidade.

Oliveira (2004) ao fazer uma reflexão sobre a corporalidade percebe que existe um ponto de forte preocupação, a civilização, que ocorre em diversas formas, em tempos e espaços distintos. Os interesses de diversos sujeitos constituem-se na vigilância, punição, observação, moralização e controle sobre os corpos. Oliveira (2004) disserta que o processo civilizatório ainda não foi concluído, visto que é possível notar permanências e continuidades, e os dados apontam para esse caminho, pois existe grande resistência no discurso dos alunos e forte crítica à realidade. As pessoas participantes do estudo percebem que as mulheres se voltam para algumas áreas e os homens para outras, de forma que as áreas separam campos de interesse e atuação profissional.

É interessante notar que em 2017 algumas alunas ainda não se sentem confortáveis para praticar esportes, elas afirmaram que no momento 
das atividades coletivas acontecerem, especialmente na prática de esportes, ainda se sentem excluídas e menosprezadas, além de sentirem vergonha e menor habilidade em modalidades coletivas. Em termos percentuais $83 \%$ dos pesquisados afirmaram que realizam práticas corporais frequentemente, $45 \%$ das pessoas praticam musculação regularmente, e esportes e danças também foram citados como atividades cotidianas. Um elemento que se expressa nos dados é que dentre os estudantes sedentários nos momentos de lazer, $75 \%$ são mulheres. O estudo realizado com 550 estudantes universitários por Torquato et al. (2016) demonstra que existe uma prevalência de sedentarismo nos momentos de lazer entre as mulheres, de $71,35 \%$ contra $28,7 \%$ dos homens. Este fato tem uma série de fatores culturais, entre os quais estão, provavelmente, as relações de gênero.

A pesquisa também questionou o interesse por práticas corporais no currículo, ou seja, buscou certificar de forma individual como os discentes recebiam e avaliavam as opções apresentadas pelo curso de Educação Física. Em ordem de preferência apresentaram-se: esportes, em primeiro lugar, seguido de treinamento resistido, dança, ginástica e lutas. $O$ coletivo evidenciou entusiasmo e abertura para diversidades presentes nos elementos da cultura corporal, quando comparadas, as disciplinas de ginástica e dança obtiveram $60 \%$ de afeição entre mulheres e $40 \%$ entre os homens; nos esportes coletivos foi o contrário: $60 \%$ dos que apreciam estas disciplinas e conteúdos são homens.

A disposição para a cultura corporal está bastante hegemônica e ampla, ao se compararem os dados com outros apontamentos verifica-se que apesar de todos apreciarem esportes coletivos, os homens estão em termos numéricos bastante à frente das mulheres, já que de todos os que afirmaram praticar esportes coletivos, apenas $20 \%$ são mulheres. Esse dado reforça o que já vem sendo tratado há muito tempo, existe algo na cultura que faz com que as experiências corporais femininas não sejam tão amplas quanto as masculinas.

As relações desigualdades percebidas nas falas dos acadêmicos não são expressões individuais e isoladas, nem mistificação, são produtos das condições e limites de um determinado momento, não dependendo da vontade particular de cada um, isto é, são expressão da limitação de um tempo. Tudo o que é reproduzido através da arte, cultura e mesmo nos discursos não são ideias que não finalizam na consciência, mas respostas da materialidade, e se são construídas por humanos podem ser desenvolvidas a ponto de se transformarem. Como afirma Firestone (1976) existe uma necessidade imediata de se questionar toda a cultura ocidental, a forma como foi estabelecida, e para isso é preciso inclusive questionar a natureza. 
Como bem avalia a autora, biologicamente as mulheres se diferenciam dos homens por suas características sexuais primárias e secundárias, enquanto, no plano cultural, a sua humanidade é diferenciada devido aos comportamentos e formas de expressar as emoções. "Os sistemas e papéis sexuais dividem a experiência humana. Os homens e as mulheres vivem nessas diferentes metades da realidade, a cultura reflete isso" (FIRESTONE, 1976, p. 63). O sistema sexo e gênero pode ser um marcador da limitação cultural.

Existem socialmente algumas noções estabelecidas para se definir os comportamentos de homens e mulheres. Enquanto os homens são cobrados por características como a força, a agressividade e o domínio, as mulheres recebem um maior nível de pressão cultural. De acordo com Goellner (1999), as mulheres precisam ser belas, magras, graciosas, submissas, maternais e virtuosas. Por sua vez, Firestone (1976) ainda acrescenta ao modo feminino de ser termos como dona de casa, reprodutoras, frustradas, dependentes, inferiores, obedientes, secundárias, meigas, inseguras, românticas, excluídas e reprimidas sexualmente.

\section{CONSIDERAÇÕES}

Este estudo demonstra que ao se analisarem as questões da educação de gênero mediadas pelas interfaces ou no corpo, é possível identificar que este processo ainda obedece a padrões tradicionais e o seu contexto é marcado por regras definidas pelas classes dominantes.

No plano da realidade vemos as mulheres com maiores restrições, vulneráveis em relação ao acesso aos bens sociais, são limitadas em termos de equiparação salarial, têm o corpo mais sujeito a violações, e ainda não são livres para lidar com a própria corporalidade, uma vez que a marca do sexo delimita movimentos e espaços, mesmo quando são permitidos.

Do próprio ponto de vista corporal ainda existem entre as pessoas investigadas, todas universitárias, preferências consideradas hegemônicas do ponto de vista dos comportamentos de gênero. Apesar de alguns homens, nesta pesquisa, conseguirem apresentar perspectivas de gênero e sexualidade consideradas diferenciadas, aparentemente, as suas práticas corporais ainda são vistas pelo viés dos seus marcadores biológicos, aspecto a ser mais bem investigado em outros estudos. 
GENDER RELATIONS IN THE BODY: STUDENTS `VIEWS OF EDUCATION IN PHYSICAL EDUCATION

ABSTRACT: Seeking to identify how gender issues cross and constitute relationships, this work aims to analyze how gender relations have been treated, from the body perspective, by undergraduate students of Physical Education in the city of Goiânia. This is a descriptive cross-sectional study, and the research was done at two Physical Education courses of public institutions of Goiânia. In order to collect data it was used the technique questionnaire, applied to 24 academics. The study demonstrates that even though some people exhibit gender and sexuality behaviors distinct from the traditional, it seems this process of education has not reached its relationship with body culture practices.

KEYWORDS: Gender. Body. Education. Physical education.

\section{LAS RELACIONES DE GÉNERO EN EL CUERPO: MIRADAS DE ESTUDIANTES DE LICENCIATURA EN EDUCACIÓN FÍSICA}

Resumen: Este trabajo tiene el objetivo de analizar cómo los académicos de las licenciaturas de Educación Física del municipio de Goiânia están trabajando con las relaciones de género a partir del cuerpo, , buscando identificar cómo las cuestiones de género atraviesan y constituyen las relaciones. El enfoque propuesto para el análisis de los datos es cualitativo. Se trata de un estudio descriptivo de carácter transversal, en el que los contextos seleccionados para el estudio fueron dos cursos de Educación Física de instituciones públicas de la ciudad de Goiânia. Para la recolección de los datos se utilizó un cuestionario aplicado a 24 académicos. El estudio demuestra que aunque algunas personas demuestran comportamientos de género y sexualidad distintos de lo tradicional, este proceso de educación parece no haber alcanzado su relación con las prácticas de la cultura corporal.

Palabras clave: Género. Cuerpo. Educación. Educación física.

NotA

1 Partimos aqui da ideia marxista de natureza, entendida como tudo aquilo que é externo a cada ser humano. Desse modo, ao compreender a natureza, tem-se como referência a sua historicidade e, consequentemente, a cultura enquanto construção humana, convertida em concreto pensado. 


\section{REFERÊNCIAS}

AGUIAR, I. R. S.; VAZ, D. V. Diferenciais de rendimento por gênero no mercado de trabalho: uma comparação entre as regiões brasileiras. Revista da $A B E T$, João Pessoa, v. 15, n. 1, p. 49-67, jan./jun. 2016.

ALTMANN, H. Marias (e) homens nas quadras: sobre a ocupação do espaço físico escolar. Educação e Realidade, Porto Alegre, v. 24, n. 2, p. 157-174, 1999.

ALTMANN, H. SOUSA, E. S. Meninos e meninas: Expectativas corporais e implicações na educação física escolar. Cadernos CEDES. Campinas n. 48, v. 19. Agosto, 1999. Disponível em: <http://www.scielo.br/pdf/\%0D/ccedes/v19n48/v1948a04.pdf> . Acesso em: 17 mar. 2015.

BANDEIRA, L. Violência, gênero e poder: múltiplas faces. In: STEVENS, C. et al. Mulheres e violências: interseccionalidades, Brasília: Technopolitik, 2017.

BAPTISTA, T. J. R. A Educação do corpo na sociedade do capital. Curitiba: Appris, 2013.

BOMBASSARO, T.;VAZ, A. F. Sobre a formação de professores para a disciplina Educação Física em Santa Catarina (1937-1945): ciência, controle e ludicidade na educação dos corpos. Educação revistada, Curitiba, n. 33, p. 111-128, 2009.

CARDOSO, F. L. et al. Implicações do conhecimento corporal no comportamento sexual. Revista brasileira de educação física e esporte, São Paulo, v. 23, n. 4, p.345-354, dez. 2009.

CASTELANI FILHO, L. Educação Física no Brasil: história que não se conta. 4 ed. Campinas: São Paulo, 1994.

CHABAUD-RYCHETER, D. Questões de gênero nas ciências sociais "normásculas". In: CHABAUD-RYCHTER, D. et al. O gênero nas ciências sociais: releituras críticas de Max Weber a Bruno Latour. São Paulo: Editora Unesp, 2014.

FIRESTONE, S. A dialética do sexo. Rio de Janeiro: Editorial labor do Brasil. 1976.

GUEDES, M. C.. A presença feminina nos cursos universitários e nas pós-graduações: desconstruindo a idéia da universidade como espaço masculino. História, ciência e saúde-Manguinhos, Rio de Janeiro, v. 15, p. 117-132, 2008.

HANDMAN, M. Marcel Mauss e a divisão das sociedades por sexos: um programa inacabado. In: CHABAUD-RYCHTER, D. et al. O gênero nas ciências sociais: releituras críticas de Max Weber a Bruno Latour. São Paulo: Editora Unesp, 2014.

HOLMSTRON, N. Como Karl Marx pode contribuir para a compreensão do gênero. In: CHABAUD-RYCHTER, D. et al. O gênero nas ciências sociais: releituras críticas de Max Weber a Bruno Latour. São Paulo: Editora Unesp, 2014.

KIAN, A. E. Goffman da produção social do gênero à objetivação social das diferenças biológicas. In: CHABAUD-RYCHTER, D. et al. O gênero nas ciências sociais: releituras críticas de Max Weber a Bruno Latour. São Paulo: Editora Unesp, 2014. 
LOURO, G. L. O corpo educado: pedagogias da sexualidade. 2. ed. Belo Horizonte: Autêntica, 2000.

MARINHO, Inezil Penna. História da Educação Física no Brasil. São Paulo: CIA. Brasil Editora, 1984. (Exposição - Bibliografia - Legislação).

MARX, K. O 18 Brumário de Luís Bonaparte. São Paulo: Paz e Terra, 1996.

. Manuscritos Econômico-Filosóficos. 4. reimp. São Paulo: Boitempo, 2010.

MARX, Karl; ENGELS, F.. A ideologia alemã. São Paulo: Martins Fontes, 1998.

OLIVEIRA. M. A. T. Notas sobre distâncias e proximidades temporais da escolarização do corpo em um "projeto" de exegese moral: teoria crítica e história. Perspectiva, Florianópolis, v. 22, n. Especial, p. 225-245, jul./dez. 2000.

PÁDUA, L. M. de et al. Prática pedagógica e educação física escolar: questões de gênero e sexualidade entre professores de educação física da rede pública de Goiânia (GO/ Brasil). REUNIÃO ANUAL DA SBPC, 64, 2012, Goiânia. Anais... Goiânia: SBPC, 2012. Disponível em: <http://www.sbpcnet.org.br/livro/64ra/resumos/resumos/3200.htm>. Acesso em: 07 nov. 2012.

PISCITELLI, A. Recriando a (categoria) mulher? In: ALGRANTI, L. (Org.). A prática feminista e o conceito de gênero. Campinas: IFCH/Unicamp, 2002, p. 7-42. (Textos Didáticos. n. 48). SÁNCHEZ GAMBOA, S.; SANTOS FILHO, C. Pesquisa Educacional: quantidade - qualidade. 8. ed. São Paulo: Cortez, 2013.

SCHWAB, K. World economic forum 2016-2017: The Global Competitiveness Report. Geneva: World Economic Forum, 2016. Disponível em: <http://www3.weforum.org/ docs/GCR20162017/05FullReport/TheGlobalCompetitivenessReport2016-2017_FINAL.pdf>. Acesso em: 6 jun. 2017.

SOARES, C. L. Corpo, conhecimento e educação: notas esparsas. In: SOARES, C. L. (Org.). Corpo e história. Campinas: Autores Associados, 2006.

. Educação Física: raízes europeias e Brasil. 2. ed. Campinas: Autores Associados, 2001.

TORQUATO, S. C. R.; et al. Sedentarismo e alterações metabólicas entre universitários. Revista de Enfermagem da UFPI, Terezina, v. 5, n. 2, p. 16-21, abr./jun. 2016.

WALZER-LANG, Daniel. A construção do masculino: dominação das mulheres e dominação das mulheres e homofobia. Revista Estudos Feministas, p. 460-482, jul./ dez., 2001. Disponível em: <https://we.riseup.net/assets/99276/versions/1/Welzerang, $\% 20$ Daniel\%20A\%20Constru\%C3\%A7\%C3\%A30\%20do\%20Masculino\%20 Domina\%C3\%A7\%C3\%A30\%20das\%20Mulheres\%20e\%20Homofobia.pdf >. Acesso em: 20 ago. 2017. 
Kelly Cristiny Martins Evangelista: Graduada pela Universidade Estadual de Goiás (2012); especialista em docência do ensino superior (2014). Mestre em Educação pela Universidade Federal de Goiás (2018). Ministrou aulas pela Secretaria Estadual de Educação de Goiás entre 2012 e 2014 e oficinas de danças populares no projeto Mais educação em 2013. Trabalha com ênfase nas temáticas Prática Pedagósica, Educação Física Escolar, Dança, Natação, Gênero e Inclusão. Atualmente exerce atividades relacionas aos processos de inclusão no ensino superior na Universidade Estadual de Goiás.

E-mail: kellycristiny89@hotmail.com

Tadeu João Ribelro Baptista: Possui graduação (Licenciatura Plena) em Educação Física pela Escola Superior de Educação Física de Goiás, especialização em Planejamento Educacional pela Associação Salgado de Oliveira e Treinamento Esportivo pela Escola Superior de Educação Física de Goiás. É mestre em Educação Brasileira pela Universidade Federal de Goiás. É doutor em Educação pela Universidade Federal de Goiás. Professor adjunto da Universidade Federal de Goiás, onde atua como docente no curso de graduação em Educação Física e no Programa de Pós-Graduação em Educação.

E-mail: tadeujrbaptista@yahoo.com.br 
